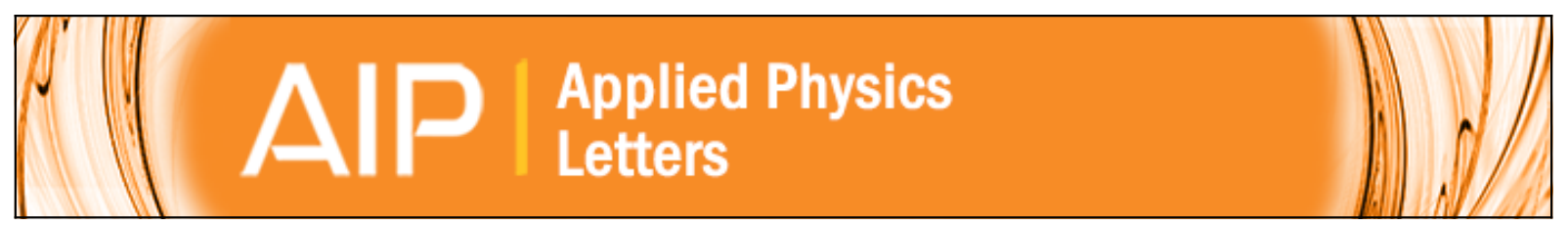

\title{
Impact of dislocations and dangling bond defects on the electrical performance of crystalline silicon thin films
}

S. Steffens, C. Becker, D. Amkreutz, A. Klossek, M. Kittler, Y.-Y. Chen, A. Schnegg, M. Klingsporn, D. Abou-Ras , K. Lips, and B. Rech

Citation: Applied Physics Letters 105, 022108 (2014); doi: 10.1063/1.4890625

View online: http://dx.doi.org/10.1063/1.4890625

View Table of Contents: http://scitation.aip.org/content/aip/journal/apl/105/2?ver=pdfcov

Published by the AIP Publishing

\section{Articles you may be interested in}

Influence of deep defects on device performance of thin-film polycrystalline silicon solar cells

Appl. Phys. Lett. 101, 123904 (2012); 10.1063/1.4754609

Stress and doping uniformity of laser crystallized amorphous silicon in thin film silicon solar cells

J. Appl. Phys. 107, 054312 (2010); 10.1063/1.3319654

Intragrain defects in polycrystalline silicon layers grown by aluminum-induced crystallization and epitaxy for thinfilm solar cells

J. Appl. Phys. 105, 114507 (2009); 10.1063/1.3117838

Dangling-bond defect state creation in microcrystalline silicon thin-film transistors

Appl. Phys. Lett. 77, 750 (2000); 10.1063/1.127107

Effect of grain size and dislocation density on the performance of thin film polycrystalline silicon solar cells J. Appl. Phys. 81, 7635 (1997); 10.1063/1.365341

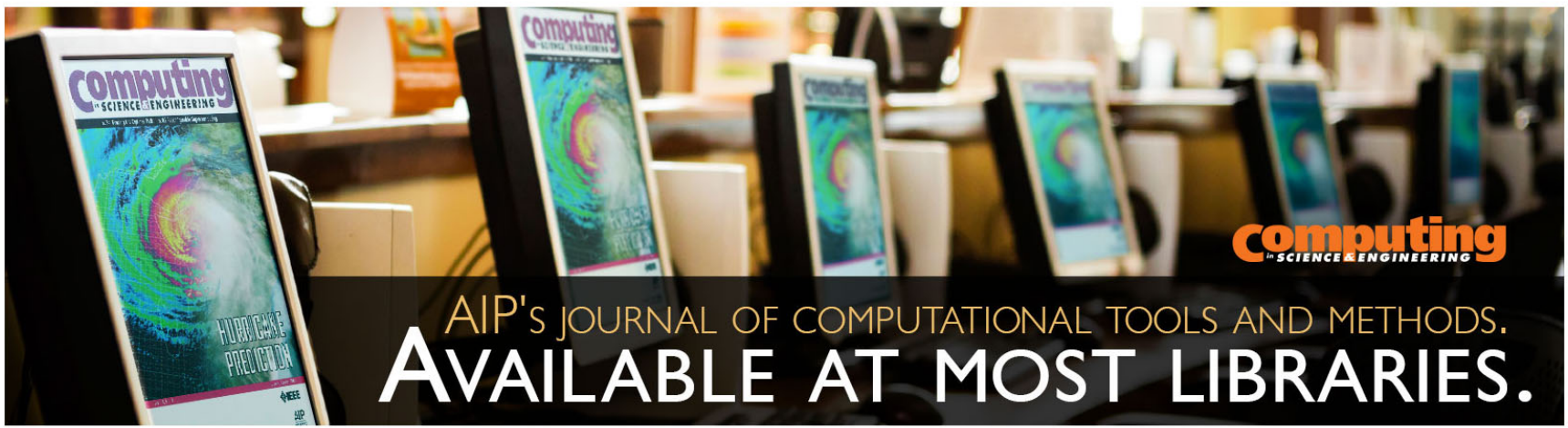




\title{
Impact of dislocations and dangling bond defects on the electrical performance of crystalline silicon thin films
}

\author{
S. Steffens, ${ }^{1}$ C. Becker, ${ }^{1}{ }^{1, a)}$ D. Amkreutz, ${ }^{1}$ A. Klossek ${ }^{2}$ M. Kittler, ${ }^{2,3}$ Y.-Y. Chen, ${ }^{1,4}$ \\ A. Schnegg, ${ }^{1}$ M. Klingsporn, ${ }^{3}$ D. Abou-Ras, ${ }^{1}$ K. Lips, ${ }^{1}$ and B. Rech ${ }^{1}$ \\ ${ }^{1}$ Helmholtz-Zentrum Berlin für Materialien und Energie, Berlin, Germany \\ ${ }^{2}$ Brandenburgische Technische Universität, Cottbus, Germany \\ ${ }^{3}$ IHP Microelectronics, Frankfurt (Oder), Germany \\ ${ }^{4}$ Green Energy and Environment Research Labs, Industrial Technology Research Institute, Hsinchu, Taiwan
}

(Received 24 June 2014; accepted 8 July 2014; published online 16 July 2014)

\begin{abstract}
A wide variety of liquid and solid phase crystallized silicon films are investigated in order to determine the performance limiting defect types in crystalline silicon thin-film solar cells. Complementary characterization methods, such as electron spin resonance, photoluminescence, and electron microscopy, yield the densities of dangling bond defects and dislocations which are correlated with the electronic material quality in terms of solar cell open circuit voltage. The results indicate that the strongly differing performance of small-grained solid and large-grain liquid phase crystallized silicon can be explained by intra-grain defects like dislocations rather than grain boundary dangling bonds. A numerical model is developed containing both defect types, dislocations and dangling bonds, describing the experimental results. (C) 2014 AIP Publishing LLC.
\end{abstract}

[http://dx.doi.org/10.1063/1.4890625]

Crystalline silicon (c-Si) thin-film solar cells on glass made great advances in the last few years since the solid phase crystallization (SPC) technology, which CSG Solar temporarily brought to industrial production, ${ }^{1}$ is superseded by emerging liquid phase crystallization (LPC) techniques. The LPC technology enabled record efficiencies of up to $11.8 \%^{2,3}$ and an excellent electronic material performance with open circuit voltages up to $650 \mathrm{mV}$ (Ref. 4) so far. Two extensive review papers describing the technological transition from the SPC to the LPC technology have been published recently. ${ }^{5,6}$ This Letter addresses current open circuit voltage $\left(V_{O C}\right)$ limitations of c-Si thin-film solar cells on glass fabricated by $\mathrm{SPC}^{1,7-9}$ and $\mathrm{LPC},{ }^{2-4,10,11}$ revealing a widespread regime of defect densities. For SPC silicon, there are two contradicting views coexisting in literature. Wong et al. claim that shallow trap states caused by dislocations are the limiting defect type and that recombination over deep defects is irrelevant for the maximum achievable $V_{O C} .{ }^{12}$ However, Fehr et al. discovered a clear dependence between the $V_{O C}$ and the density of deep dangling bond (DB) defects in the $V_{O C}$ regime of $50-360 \mathrm{mV} .{ }^{13}$ By comparing the results with numerical calculations (see also Ref. 14), the authors found that the increase in $V_{O C}$ cannot solely be explained by the reduction of DB defects and suggest either a change in the capture cross section of the defects or the influence of intragrain defects like dislocations. The second view is supported by the work of Sontheimer et al. analyzing the origin of the DB defects in c-Si thin-film material with varying grain size. ${ }^{15}$ With increasing grain size, an electron spin resonance signal can be detected which was attributed to open silicon bonds along the dislocation core ${ }^{16-18}$ revealing that upon improving the material quality the limiting defect type

\footnotetext{
${ }^{\text {a) }}$ Author to whom correspondence should be addressed. Electronic mail: christiane.becker@helmholtz-berlin.de. Tel.: +49(0)30-8062-41392.
}

changes from deep DB defects to dislocation related defect states. Experimentally, the variation of the defect densities is achieved by performing different crystallization methods, SPC and LPC, and post-crystallization processes like thermal annealing (TA) and hydrogen passivation (HP).

For SPC, a $n+/ p-/ p+$ layer stack of amorphous silicon (thicknesses $30 \mathrm{~nm} / 1.6 \mu \mathrm{m} / 50 \mathrm{~nm}$ ) is deposited on SiN coated glass substrates by electron-beam evaporation. ${ }^{9,19}$ The $n+$ emitter has a phosphorous doping of $2 \times 10^{20} \mathrm{~cm}^{-3}$. The $\mathrm{p}-$ absorber layer has a boron concentration of $2 \times 10^{16} \mathrm{~cm}^{-3}$, while the $\mathrm{p}+$ back surface field has a boron doping of $2 \times 10^{19} \mathrm{~cm}^{-3}$. SPC is done in a tube furnace at $600^{\circ} \mathrm{C}$ leading to grain sizes of $1-3 \mu \mathrm{m}$. Defect healing TA treatments, such as rapid thermal processing and laser annealing, have been used to apply plateau temperatures ranging from $900{ }^{\circ} \mathrm{C}$ to $1400^{\circ} \mathrm{C}$ for a short time $(<1 \mathrm{~min}) .^{20-26}$ For the LPC process, $10 \mu \mathrm{m}$ thick nanocrystalline silicon layers with a boron doping of around $4 \times 10^{16} \mathrm{~cm}^{-3}$ are deposited on $\mathrm{SiO}$ and $\mathrm{SiO} / \mathrm{SiC}$ coated glass substrates by electron-beam evaporation. The silicon layers are recrystallized by scanning a line-shaped electron beam focus across the sample, locally melting the silicon. ${ }^{10}$ The resolidified material features grain sizes of up to centimeters in scan direction. The LPC absorber layers are processed to solar cells using a hetero-junction cell concept described in Ref. 11. An HP process was applied to both material types for the saturation of open silicon bonds by atomic hydrogen. ${ }^{27-30}$

The numerical calculations performed in this Letter require the knowledge of the concentrations and energy levels of both defect types, the dangling bonds and the dislocations. In order to quantify the dislocation densities, crosssectional transmission electron microscopy (TEM) analysis and spatially resolved electron-beam induced current (EBIC) measurements were performed on the SPC and the LPC material, respectively. EBIC is used for the characterization of 

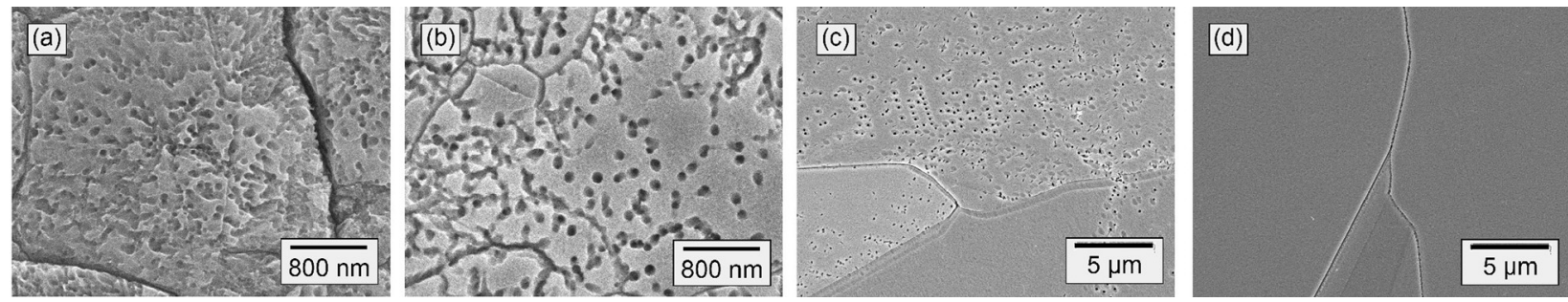

FIG. 1. Scanning electron microscope images of silicon surfaces after a Secco etch process for $4 \mathrm{~s}$. Depicted are the SPC sample without thermal annealing (a), SPC with thermal annealing at $1400^{\circ} \mathrm{C}$ (b), and the LPC material at two different positions of a sample (c) and (d).

the LPC material since the TEM sample size does not encompass the inhomogeneous dislocation density of the LPC silicon. The dislocation related radiative recombination was analyzed by photoluminescence (PL) spectroscopy. The energy levels of the D1 and D2 luminescence were measured by temperature-dependent PL. Electron spin resonance spectroscopy was used to determine the density of the paramagnetic defects which in $\mathrm{c}-\mathrm{Si}$ are mainly attributed to the unpaired spins of silicon dangling bonds. ${ }^{27,28}$ For the sake of simplicity, the simulation does not regard extrinsic impurities $^{31}$ and interface recombination which are known to limit the electronic quality of crystalline silicon solar cells.

The structural difference between the SPC and the LPC material is visualized in Fig. 1. A defect etch process was performed by exposing the samples' surface to a Secco etch solvent $^{32}$ for $4 \mathrm{~s}$. On the scanning electron microscopy images both intra-grain defects (etch pits) and grain boundaries (trenches) are visible. Etch pits appear when the disturbed material around a dislocation core (strain-field) is removed by the Secco etch. Note, that the scale is different for the SPC (a) and (b) and the LPC images (c) and (d). In Fig. 1(a), the SPC sample is depicted, which has not been processed by a rapid thermal processing technique. The entire surface of the sample is deeply etched with the grain boundaries represented by deep trenches. No apparent difference can be seen when comparing the as-crystallized sample with the samples annealed at temperatures up to $1050^{\circ} \mathrm{C}$ (not shown here). However, laser annealing above $1200^{\circ} \mathrm{C}$ leads to a reduced etch pit density (Fig. 1(b)), indicating that there are fewer defects present in the annealed state.

The Secco etched surface of the LPC silicon is shown in Fig. 1(c) and 1(d). Due to the large grain size and inhomogeneous structural quality of the LPC material, a single SEM image is not representative for the whole sample. Note, that five out of six randomly chosen sites on the sample showed no etch pits but only etched grain boundaries (Fig. 1(d)). Furthermore, the density of intra-grain defects in areas, where etch pits show the existence of dislocations, is much lower compared to the SPC samples (Figs. 1(a) and 1(b)).

In order to quantitatively measure the dislocation densities, the silicon samples have been investigated by TEM and EBIC analysis. Dislocation densities of around $10^{10} \mathrm{~cm}^{-2}$ were found in the SPC material both, before and after thermal annealing, and independent of the annealing method and temperature. The reduced etch pit density that was observed in the SEM images of the high temperature annealing (Fig. 1(b)) might be due to the annealing of the strain field of the dislocation, while the deposited energy of these thermal annealing processes is not sufficient to anneal the dislocation itself. Hartman et al. discovered that annealing times of several hours at temperatures higher than $1100^{\circ} \mathrm{C}$ are necessary to anneal dislocations in silicon. ${ }^{33}$ Such prolonged thermal processes, however, are not compatible with the low temperature glass substrates used for the c-Si solar cells. Hence, the dislocation density of the final state depends solely on the crystallization process and cannot be reduced by postprocessing. A density of $10^{10} \mathrm{~cm}^{-2}$ that is built in during SPC is inherent for this method.

EBIC analysis of the LPC material reveals an inhomogeneous material quality with dislocation densities of higher than $10^{7} \mathrm{~cm}^{-2}$ in defect-rich regions, but also defect-poor regions exist where the dislocation density can be estimated to be lower than $10^{5} \mathrm{~cm}^{-2}$, consistent with previous EBIC investigations on LPC silicon. ${ }^{34}$ For comparison, defect-rich grains in multicrystalline silicon (multi-Si) wafers have dislocation densities of $10^{4}-10^{6} \mathrm{~cm}^{-2}$. 33,35 In these regions, dislocations are considered to be the main cause for recombination losses ${ }^{36,37}$ as dislocation densities greater than $10^{4} \mathrm{~cm}^{-2}$ already enhance the recombination of minority carriers. ${ }^{38}$ Since LPC silicon exhibits similar grain sizes as the multi-Si material, it can be assumed, that the regions with dislocation densities of higher than $10^{7} \mathrm{~cm}^{-2}$ have a significant influence on the charge carrier recombination.

Knowing the density of the dislocations, their recombination activity was further investigated. PL spectra have been measured to analyze the radiative recombination paths in the c-Si thin-films. Characteristic for all SPC spectra (independent of the post-processing) is the lack of band-to-band luminescence. Only two defect induced luminescence peaks at around $0.8 \mathrm{eV}$ and $0.85 \mathrm{eV}$ can be found, which are attributed to the dislocation related luminescence peaks D1 and D2 found by Drozdov et al. ${ }^{39}$ This intense dislocation related luminescence is in accordance with the high dislocation densities revealed by the TEM analysis. The energy position of these defect states can also be estimated by $\mathrm{PL}^{40,41}$ by analyzing the luminescence intensity temperature dependent from 80 to $300 \mathrm{~K}$. With increasing temperature, the intensity decreases since more and more charge carriers are thermally activated to higher energy states. From these temperaturedependent PL measurements, it follows that the energy levels of the defect states associated with the D1 and the D2 luminescence are $163 \mathrm{meV}$ and $122 \mathrm{meV}$ below the conduction band, respectively.

Due to the spatial inhomogeneity of the dislocation density in the LPC material, as seen in the Secco etch SEM images (Fig. 1), a PL mapping was performed. The lifetime 
of the charge carriers in this material is high enough to detect band-to-band luminescence, indicating a low dislocation density and a high lifetime of the optically excited charge carriers. However, regions exist where the PL spectra are dominated by the dislocation related luminescence. Here, the band-to-band luminescence is strongly mitigated due to a higher dislocation density.

In order to quantify the dangling bond defects, the density of paramagnetic spins was measured by quantitative electron spin resonance spectroscopy. Fig. 2 shows the $V_{O C}$ of the differently processed c-Si thin-film solar cells on glass in dependence of the spin density. Open symbols represent the results after HP and filled data points represent the state before HP. While the as-crystallized SPC sample (black filled square) exhibits a spin density of $1.6 \times 10^{17} \mathrm{~cm}^{-3}$, the density is reduced down to around $5 \times 10^{16} \mathrm{~cm}^{-3}$ in case of TA (blue filled circles) and to $1 \times 10^{16} \mathrm{~cm}^{-3}$ after HP (black open square), accompanied by a $V_{O C}$ improvement of around $\Delta V_{O C}=+100 \mathrm{mV}$ and $+150 \mathrm{mV}$, respectively. Combining TA and HP (blue open circles), improvements of up to $\Delta V_{O C}=+300 \mathrm{mV}$ have been measured. The reduction of the defect density of the SPC material is mainly caused by the effective saturation of dangling bonds by atomic hydrogen upon HP processing. ${ }^{27}$ However, a reduction of the DB density by a factor of 2-3 is also achieved by thermal annealing of the SPC sample (SPC + TA), as was observed in previous studies. ${ }^{42}$ This improvement can be attributed to the restructuring of defect-rich grain boundary regions and the annealing of structural defects like stacking faults and dislocations. These extended defects consist of a series of dangling silicon bonds, e.g., the open bonds at a core of a dislocation line. ${ }^{16-18}$ Although the dislocation density is not reduced, as revealed by TEM, annealing at high temperatures can provide the energy to re-arrange the atoms at the dislocation core and support the formation of reconstructed $\mathrm{Si}-\mathrm{Si}$ bonds. ${ }^{18,43}$ The general trend of the experimental data in Fig. 2 shows that by reducing the spin density the open circuit voltage can be improved, as was found by Fehr et al. ${ }^{13}$ This trend indicates that the DB defect plays a major role in limiting the photovoltaic performance.

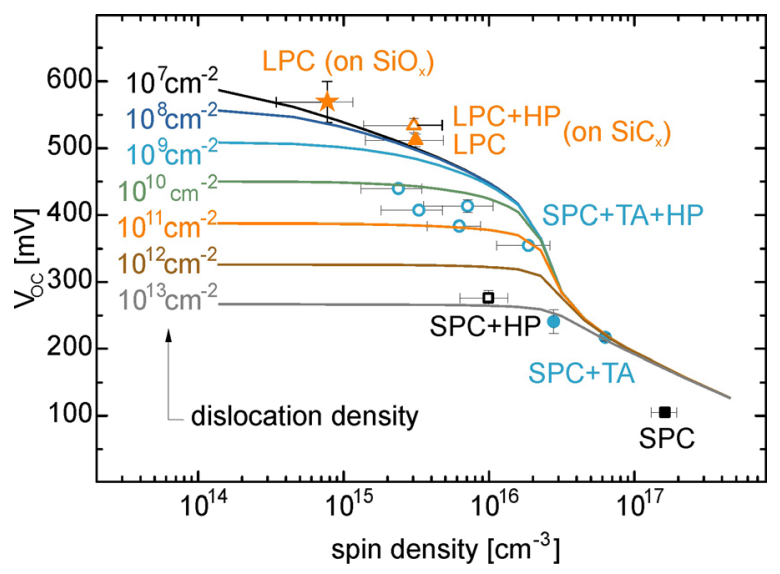

FIG. 2. Open circuit voltage of the c-Si thin-film solar cells versus the density of paramagnetic spins. Experimental results on LPC and SPC samples with optional TA and/or HP are depicted by data points. The curves show the calculated open circuit voltage of the SPC material in dependence of both, the dislocation and the dangling bond density (curves).
However, comparing the SPC + HP sample (black open square) with the completely processed $\mathrm{SPC}+\mathrm{TA}+\mathrm{HP}$ layers (blue open circles), an improvement in the $V_{O C}$ can be seen, which is accompanied by just a small change to the DB density, indicating that the thermal post-processing improves the material quality by annealing defects which are not detected by the electron spin resonance method. Furthermore, the LPC samples on $\mathrm{SiC} / \mathrm{SiO}$ coated glasses have a defect density of around $3 \times 10^{15} \mathrm{~cm}^{-3}$ (orange triangles), which is similar to the completely processed SPC samples, but have open circuit voltages of up to $540 \mathrm{mV}$, indicating that the dangling bond density is not the main difference between the SPC and the LPC material. By replacement of the $\mathrm{SiC} / \mathrm{SiO}$ interlayer stack between glass substrate and silicon by a bare $\mathrm{SiO}$ layer, the $\mathrm{DB}$ density decreases considerably to below $8 \times 10^{14} \mathrm{~cm}^{-3}$ enabling open circuit voltages around $570 \mathrm{mV}$ (orange star).

In order to evaluate to what extent the two defect types, dangling bonds and dislocations, are responsible for the limitation of the open circuit voltage, numerical calculations have been performed. Three defect states are assumed that represent the energetic states caused by the dangling bonds and dislocations (D1 and D2). The DB defect states are distributed as a Gaussian centered mid-gap between the conduction and valence band, where the integral over this distributions equals the respective defect density. ${ }^{42,44}$ The standard deviation of the Gaussian is $180 \mathrm{meV}$. The energetic position of the dislocation-related defect states are $122 \mathrm{meV}$ (D2) and $163 \mathrm{meV}$ (D1) below the conduction band, as determined by temperature-dependent PL.

The simulation calculates a recombination rate $R_{i}{ }^{45}$

$$
\begin{gathered}
R_{i}=\frac{N_{0} v_{t h}^{n} v_{t h}^{p} \sigma_{n} \sigma_{p}\left(n p-n_{\text {ieff }}^{2}\right)}{v_{t h}^{n} \sigma_{n}\left(n+\frac{n_{1}}{g_{n}}\right)+v_{t h}^{p} \sigma_{p}\left(p+\frac{p_{1}}{g_{p}}\right)}, \\
n_{1}=N_{C} \exp \left(\frac{E_{\text {trap }}-E_{C}}{k T}\right), \quad p_{1}=N_{V} \exp \left(\frac{E_{V}-E_{\text {trap }}}{k T}\right),
\end{gathered}
$$

for each of the three defect states (DB, D1, and D2), where $N_{0}$ and $E_{\text {trap }}$ are the respective defect density and defect energy level. The total recombination rate is the sum of these three rates. The material properties of the p-absorber layer summarized in Table I are those of crystalline silicon, where $\mu_{e}, \mu_{h}, N_{C}, N_{V}, v_{t h}^{n}, v_{t h}^{p}$, and $E_{g a p}=E_{C}-E_{V}$ depend on the doping concentration. ${ }^{46}$ The simulated $\mathrm{n}+/ \mathrm{p}-/ \mathrm{p}+$ structure (layer thicknesses, doping concentrations) of the model is identical to the real SPC samples. A constant surface recombination velocity of $100 \mathrm{~cm} / \mathrm{s}$ was chosen to solely investigate the influence of the bulk defects. As the capture crosssection of the DB defects is still a matter of debate in literature, a mean value of $3 \times 10^{-16} \mathrm{~cm}^{2}$ was assumed. ${ }^{47-50}$

$\mathrm{I}-\mathrm{V}$-curves are calculated for each combination of dislocation density and DB defect density. The respective $V_{O C}$ value is plotted versus the DB density in Fig. 2, where each curve represents a different dislocation density.

At DB densities larger than $10^{17} \mathrm{~cm}^{-3}$, the lines are congruent. With decreasing DB density, the curves split up and each line saturates at a certain $V_{O C}$ value, which depends on 
TABLE I. Parameters of the absorber layer.

\begin{tabular}{lcc}
\hline \hline$\mu_{e}, \mu_{h}$ & Mobilities of the charge carriers & $1076.43 \mathrm{~cm}^{2} \mathrm{~V}^{-1} \mathrm{~s}^{-1}, 400.32 \mathrm{~cm}^{2} \mathrm{~V}^{-1} \mathrm{~s}^{-1}$ \\
$v_{t h}^{n}, v_{t h}^{p}$ & Thermal velocity of the charge carriers & $1.5 \times 10^{7} \mathrm{~cm} / \mathrm{s}, 1.2 \times 10^{7} \mathrm{~cm} / \mathrm{s}$ \\
$\sigma_{n}, \sigma_{p}$ & Capture cross section & $3 \times 10^{-16} \mathrm{~cm}^{2}(D B), 8 \times 10^{-15}($ disl $)$ \\
$n_{\text {ieff }}$ & Effective, intrinsic charge carrier density & $\sim 10^{10} \mathrm{~cm}^{-3}$ \\
$g_{n}, g_{p}$ & Degeneracy factor & 1,1 \\
$N_{C}, N_{V}$ & DOS of the conduction and valence band & $2.8 \times 10^{19} \mathrm{~cm}^{-3}, 1.83 \times 10^{19} \mathrm{~cm}^{-3}$ \\
$E_{g a p}=E_{C}-E_{V}$ & Bandgap energy & $1.1238 \mathrm{eV}$ \\
$n_{1}, p_{1}$ & Shockley-Read-Hall density & Varies with $E_{\text {trap }}$ \\
$T$ & Temperature & $300 \mathrm{~K}$ \\
\hline \hline
\end{tabular}

the dislocation density. This means, that for a certain dislocation density a reduction of the DB density results in no further improvement of the $V_{O C}$ since the material quality is limited by dislocations. For the lowest dislocation density that has been investigated $\left(10^{7} \mathrm{~cm}^{-2}\right)$, there is no saturation visible in the shown regime. Hence, at low dislocation densities an improvement of the $V_{O C}$ is still possible by reducing the DB defect density.

Comparing the experimental data with the simulation, it can be seen that the influence of dislocations is only relevant for DB densities smaller than $4 \times 10^{16} \mathrm{~cm}^{-3}$, i.e., for LPC material and SPC silicon after HP (open symbols). For DB densities $>4 \times 10^{16} \mathrm{~cm}^{-3}$, i.e., the SPC material without HP, the solar cells are limited by the deep DB defects.

The experimentally measured $V_{O C}$ values of completely processed samples (open circles) are enveloped by the two lines calculated for $10^{10} \mathrm{~cm}^{-2}$ and $10^{11} \mathrm{~cm}^{-2}$, which is in excellent accordance with the measured dislocation density of $10^{10} \mathrm{~cm}^{-2}$. The simulation shows that a further reduction of the DB density will not lead to an improvement of the $V_{O C}$ unless the dislocation density is also reduced. For the hydrogen passivated SPC material, this interpretation corresponds to the assumption of Wong et al. ${ }^{12}$ that the deep DB defects have no influence on the electrical quality of the SPC silicon. The alleged contradiction between the model of Wong et al. ${ }^{12}$ and the simulations of Fehr et al. ${ }^{13}$ describing the direct dependence of the $V_{O C}$ from the DB defect density, which are also valid in their respective regime of $V_{O C}$ values and defect densities, is resolved by the investigations in this work: The limiting defect type changes during the postprocessing (TA and HP) of the SPC material. While there is a clear dependence from the DB density when analyzing the process chain of the SPC solar cells (as investigated by Fehr et $a l .{ }^{13}$ ), the influence of DB defects can be neglected after hydrogenation. In this state the dislocations embody the limiting defect type.

The DB density of $3 \times 10^{15} \mathrm{~cm}^{-3}$ found for the LPC samples on $\mathrm{SiC} / \mathrm{SiO}$ is in the same order of magnitude as the hydrogenated SPC layers (open circles). So, despite the huge difference in grain size, and thus the grain boundary to volume ratio, the crucial difference between these two materials is the density of intra-grain defects like dislocations and not the DB density. In order to reach $V_{O C}$ values higher than $500 \mathrm{mV}(600 \mathrm{mV})$, the dislocation density lower than $10^{9} \mathrm{~cm}^{-2}\left(10^{7} \mathrm{~cm}^{-2}\right)$ is required. In this regime, however, the influence of interface and surface recombination has to be taken into account.
In conclusion, the influence of dangling bond defects and dislocations on the open circuit voltage of crystalline silicon thin-film solar cells has been investigated. The densities and energy levels of the two defect types have been experimentally determined by transmission electron microscopy, electron beam induced current, photoluminescence, and electron spin resonance spectroscopy. A comparison of experimental data and numerical simulations revealed that silicon dangling bonds are the limiting defect type of the c-Si films for densities larger $4 \times 10^{16} \mathrm{~cm}^{-3}$. At spin densities lower than $4 \times 10^{16} \mathrm{~cm}^{-3}$, the maximum achievable $V_{O C}$ depends strongly on the dislocation density. The results indicate that the main difference between the small grained SPC and the large grained LPC is not grain boundary defects but the density of dislocations.

The authors are thankful for financial support from the European Commission, within the FP7-Project PolySiMode (No. 240826). We are indebted to all our project partners for fruitful discussions. In particular, we would like to thank A. Chowdhury (InESS Strasbourg) for laser annealing experiments, U. Schubert (SunTech R\&D Australia) for hydrogenation processing, and P. Plocica, S. Common, M. Muske, K. Jakob, and C. Klimm (all HZB) for technological support. The German Federal Ministry of Education and Research is acknowledged for supporting CB in the program NanoMatFutur (03X5520). The work was partially financed by the German BMBF ministry and the state government of Berlin (SENBWF) within the framework of the program "Spitzenforschung und Innovation in den Neuen Ländern" (Grant No. 03IS2151G,F). The content is at the responsibility of the authors.

${ }^{1}$ M. A. Green, P. A. Basore, N. Chang, D. Clugston, R. Egan, R. Evans, D. Hogg, S. Jarnason, M. Keevers, P. Lasswell, J. O'Sullivan, U. Schubert, A. Turner, S. R. Wenham, and T. Young, Sol. Energy 77, 857 (2004).

${ }^{2}$ J. Dore, D. Ong, S. Varlamov, R. Egan, and M. A. Green, IEEE J. Photovolt. 4, 33 (2014).

${ }^{3}$ D. Amkreutz, J. Haschke, L. Korte, F. Ruske, and B. Rech, in Proceedings of the 40th IEEE PVSC, Denver, USA (2014).

${ }^{4}$ J. Haschke, D. Amkreutz, L. Korte, F. Ruske, and B. Rech, Sol. Energy Mater. Sol. Cells 128, 190 (2014).

${ }^{5}$ C. Becker, D. Amkreutz, T. Sontheimer, V. Preidel, D. Lockau, J. Haschke, L. Jogschies, C. Klimm, J. Merkel, P. Plocica, S. Steffens, and B. Rech, Sol. Energy Mater. Sol. Cells 119, 112 (2013).

${ }^{6}$ S. Varlamov, J. Dore, R. Evans, D. Ong, B. Eggleston, O. Kunz, U. Schubert, T. Young, J. Huang, T. Soderstrom, K. Omaki, K. Kim, A. Teal, M. Jung, J. Yun, Z. Pakhuruddin, R. Egan, and M. Green, Sol. Energy Mater. Sol. Cells 119, 246 (2013). 
${ }^{7}$ T. Matsuyama, N. Terada, T. Baba, T. Sawada, S. Tsuge, K. Wakisaka, and S. Tsuda, J. Non-Cryst. Solids 198-200, 940 (1996).

${ }^{8}$ M. Keevers, T. Young, U. Schubert, and M. A. Green, in Proceedings of the 22nd European Photovoltaic Solar Energy Conference, Milan, Italy (2007), pp. 1783-1790.

${ }^{9}$ T. Sontheimer, C. Becker, F. Ruske, C. Klimm, U. Bloeck, S. Gall, O. Kunz, T. Young, R. Egan, J. Hüpkes, and B. Rech, in Proceedings of the 35th IEEE Photovoltaic Specialists Conference, Hawaii, USA (2010), pp. 614-619.

${ }^{10}$ D. Amkreutz, J. Müller, M. Schmidt, T. Hänel, and T. F. Schulze, Prog. Photovolt. Res. Appl. 19, 937 (2011).

${ }^{11}$ J. Haschke, L. Jogschies, D. Amkreutz, L. Korte, and B. Rech, Sol. Energy Mater. Sol. Cells 115(7), 7-10 (2013).

${ }^{12}$ J. Wong, J. L. Huang, B. Eggleston, M. A. Green, O. Kunz, R. Evans, M. Keevers, and R. J. Egan, J. Appl. Phys. 107, 123705 (2010).

${ }^{13}$ M. Fehr, P. Simon, T. Sontheimer, C. Leendertz, B. Gorka, A. Schnegg, B. Rech, and K. Lips, Appl. Phys. Lett. 101, 123904 (2012).

${ }^{14}$ A.-M. Teodoreanu, C. Leendertz, T. Sontheimer, L. Korte, and B. Rech, Sol. Energy Mater. Sol. Cells 117, 152 (2013).

${ }^{15}$ T. Sontheimer, A. Schnegg, S. Steffens, F. Ruske, D. Amkreutz, K. Lips, and B. Rech, Phys. Status Solidi RRL 7, 959 (2013).

${ }^{16}$ W. Shockley, Phys. Rev. 91, 1563 (1953).

${ }^{17}$ P. B. Hirsch, Mater. Sci. Technol. 1, 666 (1985).

${ }^{18}$ M. S. Duesbery and G. Y. Richardson, Crit. Rev. Solid State Mater. Sci. 17, 1 (1991).

${ }^{19}$ S. Steffens, C. Becker, J.-H. Zollondz, A. Chowdhury, A. Slaoui, S. Lindekugel, U. Schubert, R. Evans, and B. Rech, Mater. Sci. Eng. B 178, 670 (2013).

${ }^{20}$ P. Doshi, A. Rohatgi, M. Ropp, Z. Chen, D. Ruby, and D. L. Meier, Sol. Energy Mater. Sol. Cells 41-42, 31 (1996).

${ }^{21}$ F. N. Cubaynes, P. A. Stolk, J. Verhoeven, F. Roozeboom, and P. H. Woerlee, Mater. Sci. Semicond. Process. 4, 351 (2001).

${ }^{22}$ M. L. Terry, A. Straub, D. Inns, D. Song, and A. G. Aberle, Appl. Phys. Lett. 86, 172108 (2005).

${ }^{23}$ M. L. Terry, D. Inns, and A. G. Aberle, Adv. OptoElectron. 2007, 83657 (2007).

${ }^{24}$ B. Rau, T. Weber, B. Gorka, P. Dogan, F. Fenske, K. Y. Lee, S. Gall, and B. Rech, Mater. Sci. Eng. B 159-160, 329 (2009).

${ }^{25}$ A. Chowdhury, J. Schneider, J. Dore, F. Mermet, and A. Slaoui, Appl. Phys. A 107, 653 (2012).
${ }^{26}$ S. Lindekugel, L. Flatten, S. Janz, and J. Dore, in Proceedings of the 26th European Photovoltaic Solar Energy Conference, Hamburg, Germany (2011), pp. 2779-2783.

${ }^{27}$ N. M. Johnson, D. K. Biegelsen, and M. D. Moyer, Appl. Phys. Lett. 40, 882 (1982).

${ }^{28}$ N. H. Nickel, N. M. Johnson, and W. B. Jackson, Appl. Phys. Lett. 62, 3285 (1993).

${ }^{29}$ S. J. Pearton, J. W. Corbett, and T. S. Shi, Appl. Phys. A 43, 153 (1987).

${ }^{30}$ B. Gorka, B. Rau, P. Dogan, C. Becker, F. Ruske, S. Gall, and B. Rech, Plasma Processes Polym. 6, S36 (2009).

${ }^{31}$ J. R. Davis, A. Rohatgi, R. H. Hopkins, P. D. Blais, P. Rai-Choudhury, J. R. McCormick, and H. C. Mollenkopf, IEEE Trans. Electron Devices 27, 677 (1980).

${ }^{32}$ F. Secco d'Aragona, J. Electrochem. Soc. 119, 948 (1972).

${ }^{33}$ K. Hartman, M. Bertoni, J. Serdy, and T. Buonassisi, Appl. Phys. Lett. 93, 122108 (2008).

${ }^{34}$ W. Seifert, D. Amkreutz, T. Arguirov, H. M. Krause, and M. Schmidt, Solid State Phenomena 178-179, 116 (2011).

${ }^{35}$ M. Rinio, S. Peters, M. Werner, A. Lawerenz, and H. J. Möller, Solid State Phenom. 82-84, 701 (2002).

${ }^{36}$ B. Sopori and W. Chen, J. Cryst. Growth 210, 375 (2000).

${ }^{37}$ G. Stokkan, S. Riepe, O. Lohne, and W. Warta, J. Appl. Phys. 101, 053515 (2007).

${ }^{38}$ C. Donolato, J. Appl. Phys. 84, 2656 (1998).

${ }^{39}$ N. A. Drozdov, A. A. Patrin, and V. D. Tkachev, Sov. Phys. JETP Lett. 23, 597 (1976).

${ }^{40}$ M. Suezawa, Y. Sasaki, and K. Sumino, Phys. Status Solidi A 79, 173 (1983).

${ }^{41}$ R. Sauer, C. Kisielowski-Kemmerich, and H. Alexander, Phys. Rev. Lett. 57, 1472 (1986).

${ }^{42}$ M. Hirose, M. Taniguchi, and Y. Osaka, J. Appl. Phys. 50, 377 (1979).

${ }^{43}$ R. Nunes, J. Bennetto, and D. Vanderbilt, Phys. Rev. B 57, 10388 (1998).

${ }^{44}$ W. B. Jackson, Appl. Phys. Lett. 43, 195 (1983).

${ }^{45}$ S. M. Sze, Semiconductor Devices: Physics and Technology, 2nd ed. (Wiley, New York, 2002), pp. 63-65.

${ }^{46}$ G. Masetti, M. Severi, and S. Solmi, IEEE Trans. Electron Devices 30, 764 (1983).

${ }^{47}$ R. A. Street, Appl. Phys. Lett. 41, 1060 (1982).

${ }^{48}$ R. A. Street, J. Zesch, and M. J. Thompson, Appl. Phys. Lett. 43, 672 (1983).

${ }^{49}$ R. Meaudre and M. Meaudre, Philos. Mag. Lett. 82, 303 (2002).

${ }^{50}$ R. Meaudre and M. Meaudre, Appl. Phys. Lett. 85, 245 (2004). 